\title{
Digital Waveguide Modeling of Woodwind Toneholes
}

\author{
Gary P. Scavone \\ gary@ccrma.stanford.edu \\ Julius O. Smith, III \\ jos@ccrma.stanford.edu \\ Center for Computer Research in Music and Acoustics (CCRMA) \\ Department of Music, Stanford University \\ Stanford, California 94305 USA
}

\begin{abstract}
This paper demonstrates a digital waveguide implementation of a six-hole woodwind tonehole lattice, based on theory and measurements published by Keefe (1981). Woodwind tonehole transmission-matrix parameters are converted to traveling-wave scattering parameters suitable for digital waveguide implementation. Second-order digital filters are designed to approximate the reflection and transmission transfer functions implied by the Keefe data. In this way, the tonehole is implemented by a two-port scattering junction which accounts for both series and shunt complex impedances. Alternatively, the tonehole can be implemented as a one-multiply, one-filter, threeport scattering junction. The results of a digital waveguide six-hole flute bore implementation using both models are compared to Keefe (1990), with excellent agreement. In this way, the best available acoustic theory regarding toneholes is efficiently and accurately simulated in discrete-time.
\end{abstract}

\section{Two-Port Tonehole Model}

The fundamental acoustic properties of toneholes have been extensively studied and reported by Keefe (1981, 1990). The model described by Keefe (1990) is an accurate representation for a tonehole unit, assuming adjacent tonehole interactions are negligible. In this description, acoustic variables at the tonehole junction are related by a transmission matrix of series and shunt impedance parameters. Keefe's original derivation of the tonehole parameters was based on a symmetric $T$ section, as shown in Fig. 1 (Keefe, 1981). The series impedance terms, $Z_{a}$, result from

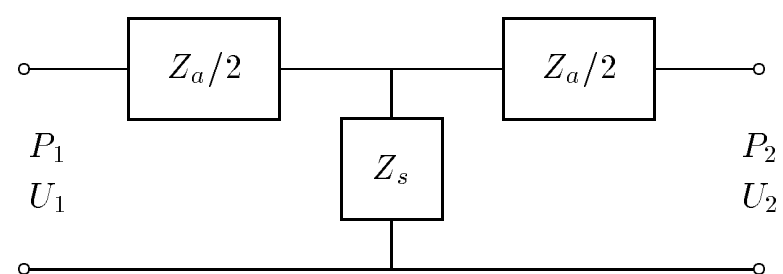

Fig. 1: $T$ section transmission-line representation of the tonehole.

an analysis of anti-symmetric pressure distribution, or a pressure node, at the tonehole junction. In this case, volume flow is symmetric and equal across the junction. The shunt impedance term, $Z_{s}$, results from an analysis of symmetric pressure distribution, or a pressure anti-node, at the tonehole, for which pressure is symmetric and equal across the junction. The transmission matrix which results under this analysis is given by

$$
n\left[\begin{array}{c}
P_{1} \\
U_{1}
\end{array}\right]=\left[\begin{array}{cc}
1+\frac{Z_{a}}{2 Z_{s}} & Z_{a}\left(1+\frac{Z_{a}}{4 Z_{s}}\right) \\
Z_{s}^{-1} & 1+\frac{Z_{a}}{2 Z_{s}}
\end{array}\right]\left[\begin{array}{c}
P_{2} \\
U_{2}
\end{array}\right],
$$

obtained by cascading the three matrices which correspond to the three impedance terms. Based on the approximation that $\left|Z_{a} / Z_{s}\right| \ll 1$, Eq. (1) can be reduced to the form

$$
\left[\begin{array}{c}
P_{1} \\
U_{1}
\end{array}\right]=\left[\begin{array}{cc}
1 & Z_{a} \\
Z_{s}^{-1} & 1
\end{array}\right]\left[\begin{array}{c}
P_{2} \\
U_{2}
\end{array}\right]
$$

which is the basic tonehole unit cell given by Keefe for transmission-matrix calculations. The values of $Z_{a}$ and $Z_{s}$ vary according to whether the tonehole is open (o) or closed (c) as

$$
\begin{aligned}
Z_{s}^{(o)} & =Z_{0}(a / b)^{2}\left(j k t_{e}+\xi_{e}\right), \\
Z_{s}^{(c)} & =-j Z_{0}(a / b)^{2} \cot (k t), \\
Z_{a}^{(o)} & =-j Z_{0}(a / b)^{2} k t_{a}^{(o)}, \\
Z_{a}^{(c)} & =-j Z_{0}(a / b)^{2} k t_{a}^{(c)} .
\end{aligned}
$$

Definitions and descriptions of the various parameters in Eqs. (3a) - (3d) can be found in (Keefe, 1990). 
To render these relationships in the digital waveguide domain, it is necessary to transform the planewave physical variables of pressure and volume velocity to traveling-wave variables as

$$
\left[\begin{array}{c}
P_{1} \\
U_{1}
\end{array}\right]=\left[\begin{array}{c}
P_{1}^{+}+P_{1}^{-} \\
Z_{0}^{-1}\left(P_{1}^{+}-P_{1}^{-}\right)
\end{array}\right],
$$

where $Z_{0}$ is the characteristic impedance of the cylindrical bore, which is equal on both sides of the tonehole. Waveguide pressure variables on both sides of the tonehole are then related by

$$
\left[\begin{array}{c}
P_{1}^{-} \\
P_{2}^{+}
\end{array}\right]=\left[\begin{array}{cc}
\mathcal{R}^{-} & \mathcal{T}^{-} \\
\mathcal{T}^{+} & \mathcal{R}^{+}
\end{array}\right]\left[\begin{array}{l}
P_{1}^{+} \\
P_{2}^{-}
\end{array}\right]
$$

where

$$
\begin{aligned}
& \mathcal{R}^{-}=\mathcal{R}^{+} \approx \frac{Z_{a} Z_{s}-Z_{0}^{2}}{Z_{a} Z_{s}+2 Z_{0} Z_{s}+Z_{0}^{2}}, \\
& \mathcal{T}^{-}=\mathcal{T}^{+} \approx \frac{2 Z_{0} Z_{s}}{Z_{a} Z_{s}+2 Z_{0} Z_{s}+Z_{0}^{2}},
\end{aligned}
$$

calculated using Eqs. (1) and (4) and then making appropriate simplifications for $\left|Z_{a} / Z_{s}\right| \ll 1$. Figure 2 depicts the waveguide tonehole two-port scattering junction in terms of these reflectances and transmittances. This structure is analogous to the fourmultiply Kelly-Lochbaum scattering junction (Kelly and Lochbaum, 1962).

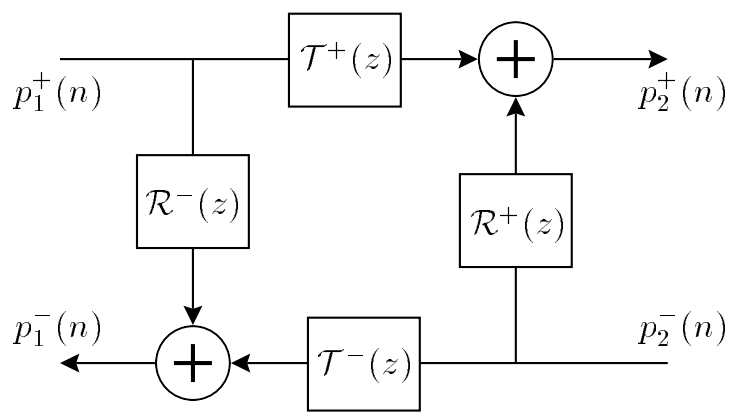

Fig. 2: Digital waveguide tonehole two-port scattering junction.

For the implementation of the reflectances and transmittances given by Eqs. (6a) - (6b) in the digital waveguide structure of Fig. 2, it is necessary to convert the continuous-time filter responses to appropriate discrete-time representations. In this study, use is made of an equation-error minimization technique (Smith, 1983) which matches both frequency response magnitude and phase. This technique is implemented in $M A T L A B^{\circledR}$ by the function invfreqz. Figure 3 plots the responses of second-order discretetime filters designed to approximate the continuoustime magnitude and phase characteristics of the reflectances for closed and open toneholes. The openhole discrete-time filter was designed using Kopec's method (Smith, 1983, p. 46), in conjunction with the equation-error method. That is, a one-pole model $\hat{H}_{1}(z)$ was first fit to the continuous-time response, $H\left(e^{j \Omega}\right)$. Subsequently, the inverse error spectrum, $\hat{H}_{1}\left(e^{j \Omega}\right) / H\left(e^{j \Omega}\right)$ was modeled with a two-pole digital filter, $\hat{H}_{2}(z)$. The discrete-time approximation to $H\left(e^{j \Omega}\right)$ was then given by $\hat{H}_{1}(z) / \hat{H}_{2}(z)$. The first step of this design process captures the peaks of the spectral envelope, while the second step models the "dips" in the spectrum. These particular calculations were performed for a tonehole of radius $b=4.765 \mathrm{~mm}$, minimum tonehole height $t_{w}=3.4 \mathrm{~mm}$, tonehole radius of curvature $r_{c}=0.5 \mathrm{~mm}$, and air column radius $a=9.45 \mathrm{~mm}$. The results of Keefe (1981) were experimentally calibrated for frequencies less than about 5 $\mathrm{kHz}$, so that the continuous-time responses evident in the figures are purely theoretical above this limit. Therefore, the discrete-time filter design process was weighted to produce better matching at low frequencies.
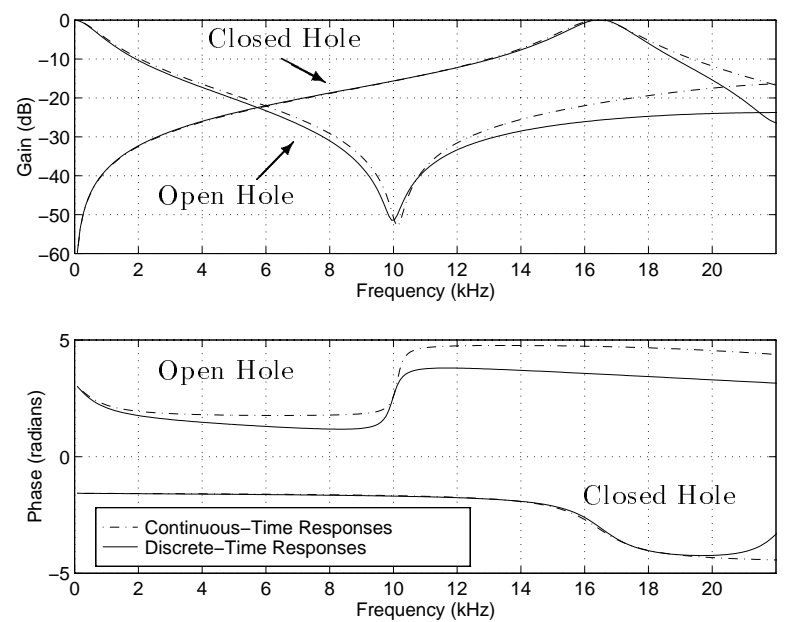

Fig. 3: Two-port tonehole junction closed-hole and open-hole reflectances, derived from Keefe (1981) shunt and series impedance parameters. (top) Reflectance magnitude; (bottom) Reflectance phase.

Figure 4 plots the reflection function calculated for a six-hole flute bore, as described in (Keefe, 1990). The upper plot was calculated using Keefe's frequency-domain transmission matrices, such that the reflection function was determined as the inverse Fourier transform of the corresponding reflection coefficient. This response is equivalent to that provided by Keefe (1990), though scale factor discrepancies exist due to differences in open-end reflection models and lowpass filter responses. The lower plot was calculated from a digital waveguide model using twoport tonehole scattering junctions. Differences between the continuous- and discrete-time results are 

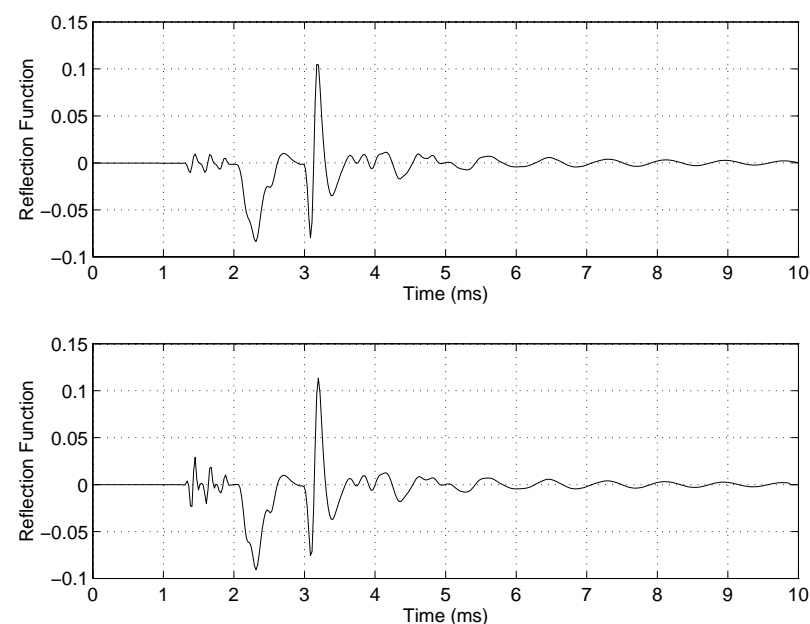

Fig. 4: Reflection functions for note $G$ (three finger holes closed, three finger holes open) on a simple flute [see (Keefe, 1990)]. (top) Transmission-line calculation; (bottom) Digital waveguide two-port tonehole implementation.

most apparent in early, high-frequency, closed-hole reflections. The continuous-time reflection function was low-pass filtered to remove time-domain aliasing effects incurred by the inverse Fourier transform operation and to better correspond with the plots of (Keefe, 1990). By trial and error, a lowpass filter with a cutoff frequency around $4 \mathrm{kHz}$ was found to produce the best match to Keefe's results. The digital waveguide result was obtained at a sampling rate of $44.1 \mathrm{kHz}$ and then lowpass filtered to a $10 \mathrm{kHz}$ bandwidth, corresponding to that of (Keefe, 1990). Further lowpass filtering is inherent from the first-order Lagrangian, delay-line length interpolation technique used in this model (Välimäki, 1995). Because such filtering is applied at different locations along the "bore," a cumulative effect is difficult to accurately determine. The first tonehole reflection is affected by only two interpolation filters, while the second tonehole reflection is affected by four of these filtering operations. This effect is most responsible for the minor discrepancies apparent in the plots.

\section{Three-Port Tonehole Model}

A tonehole junction may also be represented in the digital waveguide context by a lossless three-port junction. The three-port junction models sound wave interaction at the intersection of the air column and tonehole, as determined by conservation of volume flow and continuity of pressure. Wave propagation within the tonehole itself can subsequently be modeled by another waveguide and the reflection/transmission characteristics at its end by an appropriate digital filter. This tonehole model is then attached to the appropriate branch of the three-port junction. The bore characteristic admittance $Y_{0}$ is equal on either side of the junction, while the real tonehole characteristic admittance is $Y_{0 t h}$.

The three-port scattering junction equations for pressure traveling-wave components can be determined as

$$
\begin{aligned}
& p_{a}^{-}(t)=r_{0} p_{a}^{+}(t)+\left[1+r_{0}\right] p_{b}^{-}(t) \\
& -2 r_{0} p_{t h}^{-}(t) \\
& p_{b}^{+}(t)=\left[1+r_{0}\right] p_{a}^{+}(t)+r_{0} p_{b}^{-}(t) \\
& -2 r_{0} p_{t h}^{-}(t) \\
& p_{t h}^{+}(t)=\left[1+r_{0}\right] p_{a}^{+}(t)+\left[1+r_{0}\right] p_{b}^{-}(t) \\
& -\left[1+2 r_{0}\right] p_{t h}^{-}(t),
\end{aligned}
$$

where

$$
r_{0}=\frac{-Y_{0 t h}}{Y_{0 t h}+2 Y_{0}}=\frac{-Z_{0}}{Z_{0}+2 Z_{0 t h}} .
$$

A one-multiply form of the three-port scattering equations is given by

$$
\begin{aligned}
p_{a}^{-}(t) & =p_{b}^{-}(t)+w \\
p_{b}^{+}(t) & =p_{a}^{+}(t)+w \\
p_{t h}^{+}(t) & =p_{a}^{+}(t)+p_{b}^{-}(t)-p_{t h}^{-}(t)+w
\end{aligned}
$$

where

$$
w=r_{0}\left[p_{a}^{+}(t)+p_{b}^{-}(t)-2 p_{t h}^{-}(t)\right] .
$$

An implementation of these equations in shown in Fig. 5.

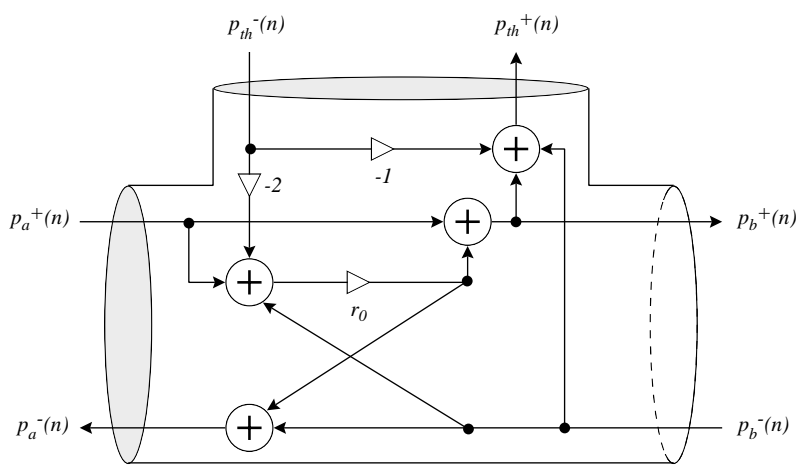

Fig. 5: Tonehole three-port scattering junction implementation in one-multiply form.

To complete the digital waveguide three-port tonehole implementation, it is necessary to determine an appropriate model for the tonehole section itself, and then attach this model to the junction. It is 
possible to implement the tonehole structure as a short, fractional delay, digital waveguide and apply an appropriate reflectance at its end. Depending on the tonehole geometry, the reflectance at the end of an open tonehole may be determined from either a flanged or unflanged (Levine and Schwinger, 1948) pipe approximation. The far end of a closed tonehole is appropriately modeled by an infinite impedance (or a pressure reflection without inversion). Given typical tonehole heights, however, a lumped reflectance model of the tonehole, which accounts for both the propagation delay and end reflection is more appropriate and easily implemented with a single low-order digital filter. In this sense, incoming tonehole pressure $p_{t h}^{-}(t)$ is calculated from the outgoing tonehole pressure $p_{t h}^{+}(t)$ and the lumped tonehole driving point reflectance, while the corresponding pressure radiated from the open tonehole is given by convolution of $p_{t h}^{+}(t)$ with the lumped tonehole section transmittance. Figure 6 plots the reflection function obtained for the six-hole flute bore implemented using digital waveguide three-port tonehole junctions. The lumped open-hole reflectance incorporates an unflanged characteristic, while the closed-hole reflectance which best matches the Keefe (1990) data includes no propagation delay within the side branch. Alternatively, the lumped tonehole reflectance filters can be designed from the shunt impedance parameters of Eqs. (3a) and (3b), thus taking advantage of the data of Keefe (1981). The digital waveguide three-port tonehole junction implementation presented here corresponds to the two-port model when series impedance terms are neglected. In general, the series impedance terms are much less critical to the model performance than the shunt impedance, which is demonstrated by the similarity of the results for both implementations. Further, the series terms have more influence on closed-hole results than those for open holes (Keefe, 1981).

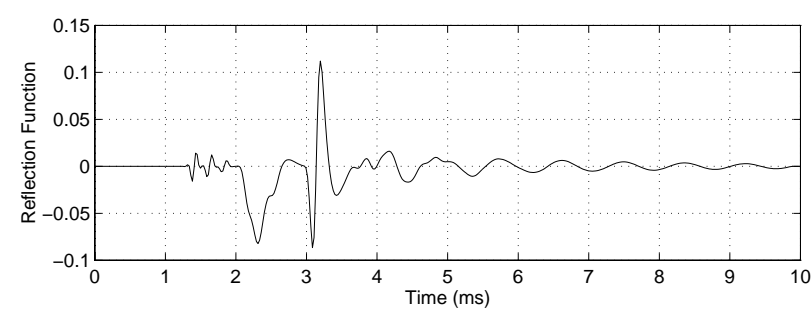

Fig. 6: Reflection function for note $G$ (three finger holes closed, three finger holes open) on a simple flute [see (Keefe, 1990)], determined using a digital waveguide three-port junction tonehole implementation.

\section{Conclusions}

Current theoretical models of woodwind finger holes can be accurately implemented in the digital waveguide domain. The two-port tonehole waveguide implementation requires four second-order filtering operations per tonehole (details regarding a one-filter form are to be published in the proceedings of the 1997 IEEE Workshop on Applications of Signal Processing to Audio and Acoustics). The three-port implementation requires one multiply and one filtering operation. The results for both implementations are very similar, despite the fact that the three-port model neglects the series impedance terms. A more complete and detailed analysis of this topic, unconstrained by page number limitations, can be found in (Scavone, 1997).

\section{References}

Keefe, D. H. (1981). Woodwind Tone-hole Acoustics and the Spectrum Transformation Function. Ph.D. thesis, Case Western Reserve University.

Keefe, D. H. (1990). Woodwind air column models. J. Acoust. Soc. Am., 88(1):35-51.

Kelly, Jr., J. L. and Lochbaum, C. C. (1962). Speech synthesis. In Proc. Fourth Int. Congress on Acoustics, pp. 1-4, Copenhagen, Denmark. Paper G42.

Levine, H. and Schwinger, J. (1948). On the radiation of sound from an unflanged circular pipe. Phys. Rev., 73(4):383-406.

Scavone, G. P. (1997). An Acoustic Anaylsis of Single-Reed Woodwind Instruments with an Emphasis on Design and Performance Issues and Digital Waveguide Modeling Techniques. Ph.D. thesis, Music Dept., Stanford University. Available as CCRMA Technical Report No. STAN-M-100 or from ftp://ccrmaftp.stanford.edu/pub/Publications/Theses/GaryScavoneThesis/.

Smith, J. O. (1983). Techniques for Digital Filter Design and System Identification with Application to the Violin. Ph.D. thesis, Elec. Eng. Dept., Stanford University.

Välimäki, V. (1995). Discrete-Time Modeling of Acoustic Tubes Using Fractional Delay Filters. Ph.D. thesis, Helsinki University of Technology, Faculty of Electrical Engineering, Laboratory of Acoustic and Audio Signal Processing, Espoo, Finland, Report no. 37. 